\title{
School Lunch Environmental Factors Impacting Fruit and Vegetable Consumption
}

\author{
Ian Yi Han Ang, PhD ${ }^{1,2}$; Randi L. Wolf, PhD, $\mathrm{MPH}^{2}$; Pamela A. Koch, EdD, RD ${ }^{2}$; \\ Heewon L. Gray, PhD, RD ${ }^{3}$; Raynika Trent, MS, EdM ${ }^{2}$; Elizabeth Tipton, PhD ${ }^{4}$; \\ Isobel R. Contento, $\mathrm{PhD}^{2}$
}

\begin{abstract}
Objective: Assess impact of school lunch environmental factors on fruit and vegetable (F\&V) consumption in second and third grade students.

Design: Cross-sectional observations in 1 school year.

Participants: Students from 14 elementary schools in 4 New York City boroughs $(n=877$ student-tray observations).

Main Outcome Measure(s): Dependent variables were F\&V consumption collected by visual observation. Independent variables included school lunch environmental factors, and individual-level and schoollevel demographics.

Analysis: Hierarchical linear modeling was used with F\&V consumption as the outcome variable, and relevant independent variables included in each model.

Results: Slicing or precutting of fruits and having lunch after recess were positively associated $(P<.05)$ with .163- and .080-cup higher fruit consumption across all students, respectively. Preplating of vegetables on lunch trays, having 2 or more vegetable options, and having lunch after recess were positively associated $(P<.05)$ with .024-, .009-, and .007-cup higher vegetable consumption across all students, respectively.

Conclusions and Implications: Although there was a small increase in intake, results of the study support that some school lunch environmental factors affect children's F\&V consumption, with some factors leading to more impactful increases than others. Slicing of fruits seems most promising in leading to greater fruit consumption and should be further tested.
\end{abstract}

Key Words: fruit, vegetables, lunch, schools, students, child (J Nutr Educ Behav. 2019; 51:68-79.)

Accepted August 21, 2018. Published online October 5, 2018.

\section{INTRODUCTION}

Children in the US do not eat enough fruits and vegetables (F\&V) to meet current dietary guidelines of 1-1.5 cups of fruits, and 1.5-2 cups of vegetables per day. ${ }^{1}$ The National Cancer Institute found that for children ages 4-8 years,
$50 \%$ of boys and $68 \%$ of girls are consuming less than the recommended servings of fruits, and 95\% of both genders are consuming less than the recommended servings of vegetables. ${ }^{2}$ F\&V are an important source of various nutrients, and higher F\&V consumption during childhood has been associated with

\footnotetext{
${ }^{1}$ Regional Health System Planning Office, National University Health System, Singapore

${ }^{2}$ Department of Health and Behavior Studies, Teachers College, Columbia University, New York, NY

${ }^{3}$ Department of Community and Family Health, College of Public Health, University of South Florida, Tampa, FL

${ }^{4}$ Department of Human Development, Teachers College, Columbia University, New York, NY

Conflict of Interest Disclosure: The authors have not stated any conflicts of interest.

Address for correspondence: Ian Yi Han Ang, PhD, Regional Health System Planning Office, National University Health System, Singapore 119228, Singapore;

E-mail: yha2103@columbia.edu

(C) 2018 The Authors. Published by Elsevier Inc. on behalf of Society for Nutrition Education and Behavior. This is an open access article under the CC BY-NC-ND license. (http:// creativecommons.org/licenses/by-nc-nd/4.0/)

https://doi.org/10.1016/j.jneb.2018.08.012
}

lower risk of various chronic diseases such as cancer, cardiovascular diseases in adulthood, ${ }^{3-5}$ and even Crohn disease in childhood. ${ }^{6}$

Federal-level school-based programs have been implemented over the years as part of the efforts to increase $\mathrm{F} \& \mathrm{~V}$ consumption in US children. Examples include US Department of Agriculture (USDA) Fresh Fruit and Vegetable Program, Chefs Move to Schools Program, Salad Bars to Schools Program, Farms to Schools Grant Program, and FoodCorps. ${ }^{7}$ As part of the Healthy, Hunger Free Kids Act authorized in 2010, new USDA Nutrition Standards in the National School Lunch Program (NSLP) and School Breakfast Program increased the portion sizes of F\&V served, with the aim to increase the amount that children consume. $^{8}$ Despite some of these large-scale national efforts, we have not seen a significant increase in $F \& V$ consumption over the years. ${ }^{9,10}$ This 
is perhaps due to the complexity of factors that may influence $F \& V$ consumption, including the physical environment. $^{11-13}$

The eating and food environment includes the physical space in which one eats, how a meal progresses, and the people that we interact with during a meal. ${ }^{14}$ The eating and food environment can have a strong influence on one's food selection and food consumption. School lunch environmental factors that make up the eating and food environment in a school cafeteria can likewise have a strong influence on students' food selection and food consumption during school lunch. Analyzing these school lunch environmental factors is thus crucial in understanding how certain factors could be influencing school lunch food item selection and consumption, and could be manipulated as part of certain wellness intervention programs.

Various studies have tested school lunch environmental factors and how they affect school lunch F\&V consumption. Increase in time for the school lunch period from the standard 20-minute period to a longer 30-minute period, ${ }^{15,16}$ and scheduling recess before school lunch, ${ }^{17-20}$ have both been found to increase F\&V consumption. Preplating of F\&V options on school lunch trays such that they are the default items present on lunch trays also increases the amount of those items consumed. $^{21}$ Offering a greater variety of F\&V also increases their selection and consumption. ${ }^{22}$ For fruit items, presenting whole fruit in attractive displays, ${ }^{23}$ while slicing certain fruit items, ${ }^{24,25}$ can help increase both their selection and their consumption. Layout of where food items are placed ${ }^{26,27}$ and physical layout and design of the cafeteria $^{23,26}$ can also be key in determining the frequency of selection for a food item.

Various studies have investigated associations between school lunch environmental factors and F\&V consumption, yet most studies in this area investigate a single factor. Additionally, these studies typically have a small number of schools sampled, ${ }^{15-17,20,23-25,27}$ which limits generalizability. Some studies used consumption measurement methods with larger increments $(0 \%, 50 \%$, $100 \%)^{20-23,25}$ and thus provide lower precision in estimating consumption amounts; some studies used consumption measurement methods (24-hour recall or photography) ${ }^{19,24}$ with lower reliability when applied to children. ${ }^{28-31}$ The purpose of this study was to investigate various school lunch environmental factors simultaneously to determine the strength of each factor's impact on $\mathrm{F} \& \mathrm{~V}$ consumption in elementary school students.

\section{METHODS}

\section{Study Design}

The current investigation was a cross-sectional assessment of the impact of school lunch environmental factors (Table 1) on school lunch F\&V consumption in second and third grade students in 14 New York City (NYC) low-income urban elementary schools participating in the NSLP. Data were collected within 1 school year, over the Fall 2015 and Spring 2016 school terms. The current investigation is an analysis of data collected as part of a larger primary study evaluating the impact of 2 years of the Wellness in the Schools (WITS) programming, which is a nonprofit program that implements more scratch-cooked, less-processed meals and active recess periods to schools; the current investigation does not evaluate the WITS programming.

\section{Participants and Recruitment}

This section describes the recruitment process of the 14 schools for the larger primary study that generated the data for this study. For the 2015-2016 school year, 7 elementary schools were selected by WITS (out of their application pool) to receive WITS programming and take part in the larger primary study. For each of the 7 WITS schools, a list of potential control schools was generated following the propensity score matching approach developed by Tipton (2013), ${ }^{32}$ matching on: percentage of students eligible for free and reduced price lunch (\% FRPL), percentage of students that were Black (\% Black), percentage of students that were Hispanic (\% Hispanic), New York State Common Core English Language Arts and Math mean scale scores, and second and third grade enrollment.

Potential control schools were excluded if they met any of the following criteria: 1) previously received or were currently receiving WITS programming; 2) were currently receiving intervention programming similar to WITS; 3 ) did not serve the NYC School Food standard lunch menu or was on the vegetarian menu; 4) had an organized physical activity program during recess that was being run by an external organization; and 5) did not have a kitchen and/or an in-school cook, or caters school lunch.

The first potential control for each of the WITS schools that met all criteria and chose to participate was officially enrolled in the study after the Principal signed the NYC Department of Education (NYCDOE) Approval to Conduct Research in Schools form. We received approval from the Institutional Review Boards at Teachers College, Columbia University, and at NYCDOE. Schools were committed to participate in the 2-year time period for the main evaluation study. As part of participation incentive, control schools were offered $\$ 1,000$ to use on any nonhealth-related programming.

\section{Student Sample}

Only second and third grade students were observed for their consumption of school lunch F\&V. Lunch-trays were observed anonymously, thus, data could not be linked to individual students. A total of 877 unique anonymous-student tray observations from 14 schools were conducted, with 415 observations in Fall 2015, and 462 observations in Spring 2016.

\section{Measures}

Fruit and vegetable consumption. Students' school lunch food selection and consumption was assessed by visual observation using System of Observational Cafeteria Assessment of Foods Eaten (SOCAFE) (Figure). 


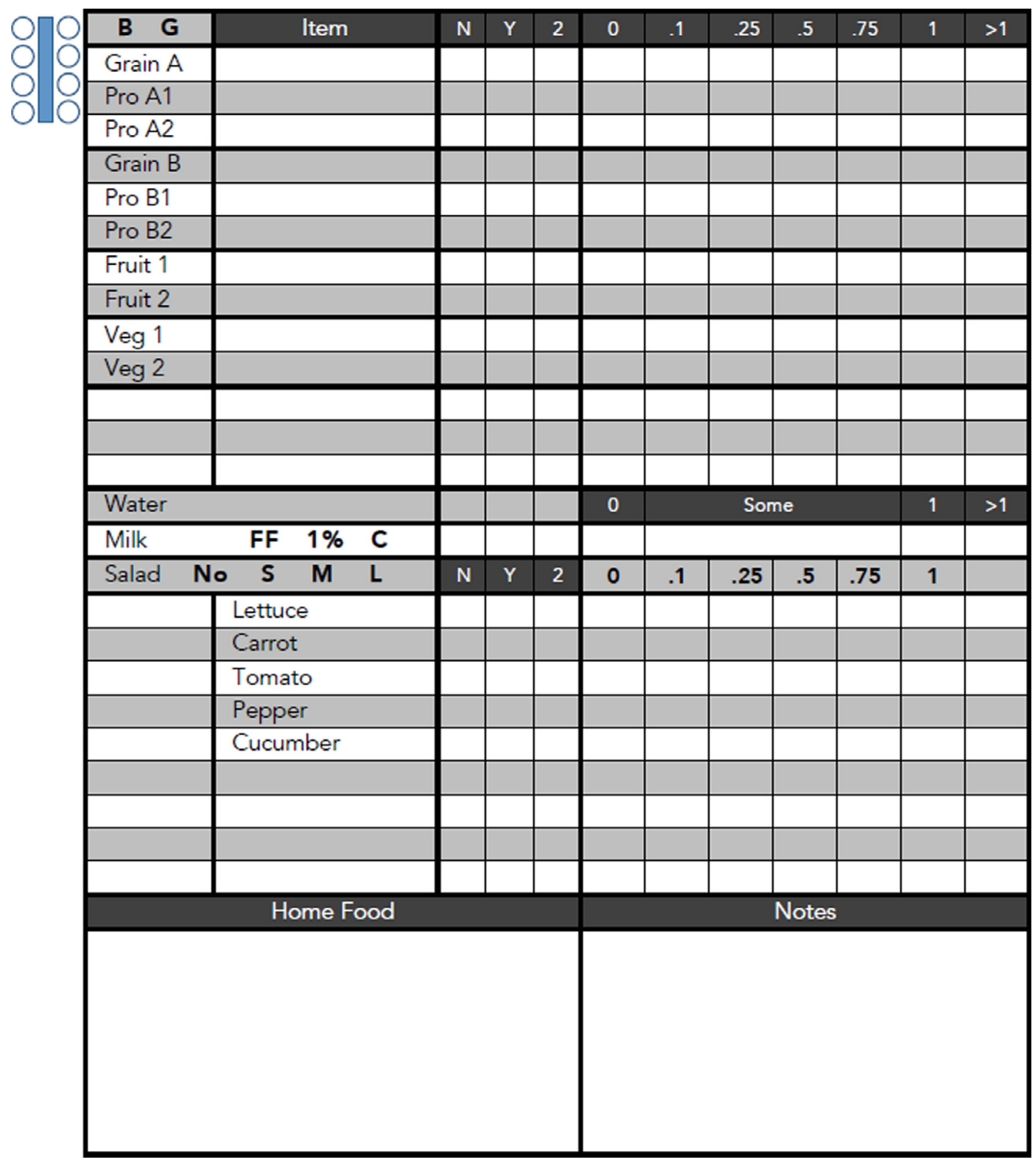

Figure. Sample quadrant of the System of Observational Cafeteria Assessment of Foods Eaten (SOCAFE) form. B indicates boy; G, girl; N, no; Y, yes; Pro, protein; FF, fat-free; C, chocolate; S, small; M, medium; L, large.

Consumption of F\&V items was observed and recorded as a percentage category of the .5-cup standard serving. The standard serving of .5 cup was used, aligning with the NSLP minimum amount per day to be served for fruits, and the minimum amount per week for 4 of the 5 vegetable categories. ${ }^{8}$ Because the percentage category consumed of each fruit or vegetable item was observed, the minimum amount per week for the vegetable category was a more logical and conservative approximation for the amount served for each vegetable item, keeping it consistent across the board at .5 cup.

The 7 percentage categories used were $0 \%, 10 \%, 25 \%, 50 \%, 75 \%$, $100 \%$, and more than $100 \%$ ( $\geq 100 \%$ ), which applied when students had more than one serving on their tray. The $10 \%$ and $\geq 100 \%$ categories were added to quarter-waste method ${ }^{31}$ to increase sensitivity. Cups of fruit or vegetable eaten were calculated by multiplying the observed percentage eaten by the standard .5 cup served. School lunch F\&V consumption data were collected on 2 days within a school year, with an average of 30 students per day for each school. 
Table 1. School Lunch Environmental Factors Relevant to Fruit Consumption or Vegetable Consumption

\section{School Lunch Environmental Factors ( $\mathbf{n}=$ Total Applicable Observed Lunch Periods)}

Categorical (yes/no)
(A) Lunch is after recess $(n=62)$
(B) Fruits are preplated on lunch trays $(n=65)$
(C) Two or more fruit options are available $(n=63)$
(D) Fruits are sliced or precut $(n=65)$
(E) Whole fruits are in an attractive serving bowl $(n=46)$
(F) Vegetables are preplated on lunch trays $(n=65)$
(G) Two or more vegetable options are available $(n=65)$
$(\mathrm{H})$ Vegetables are positioned as first item in lunch line $(n=63)$
Continuous (scale)
(I) Wait time before getting school lunch ( $\min )(n=63)$
(J) Time duration of school lunch $(\min )(n=65)$

$$
\begin{aligned}
& 19(30.7 \%) \\
& 13(20.0 \%) \\
& 20(31.8 \%) \\
& 40(61.5 \%) \\
& 19(41.3 \%) \\
& 39(60.0 \%) \\
& 11(16.9 \%) \\
& 21(33.3 \%) \\
& 4.6(0 \text { to } 23)
\end{aligned}
$$$$
14.3 \text { (4 to } 27)
$$

Frequency of Yes Response/Unadjusted Mean Value (\% / Range)
Factor is Relevant to Consumption of

$$
\text { Fruit }
$$

Vegetable

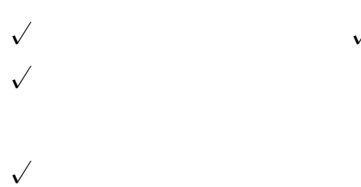

$\checkmark$

$\sqrt{ }$

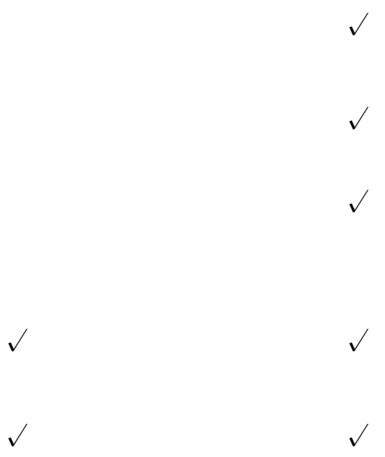

Days when white potatoes were on the menu were excluded from data collection because children's intake of white potatoes in the US is overall high and potatoes are most typically served as fried or chips. Thus, in F\&V consumption studies, white potatoes were commonly analyzed separately from consumption of other vegetables. $^{33,34}$ In NYC public elementary schools, only fresh, frozen, or canned fruit was served at school lunch. Because $100 \%$ fruit or vegetable juice was not an option, ${ }^{35}$ juice was not examined. Tables 2 and 3 summarize the various $F \& V$ item options served in the 65 observed lunch periods.

School lunch environmental factors. For the current investigation, 10 relevant school lunch environmental factors were extracted from the Lunch Process Implementation Evaluation and Contextual Environment of Schools (Lunch PIECES) instrument that was collected for school lunch periods with second and third grade students. Lunch PIECES was developed for the purposes of the larger primary study. Specific school lunch environmental factors that could potentially impact F\&V consumption were identified based on Smarter Lunchrooms Movement and research on school lunch environmental factors, ${ }^{15-27}$ with 10 factors being analyzed (Table 1). None of these factors were manipulated as part of the WITS intervention. Eight factors were categorical data (Yes/No) and 2 factors were continuous scale data. Factors were assessed for each lunch period that school lunch consumption data were collected, as these factors often varied by lunch period.

Demographics. Student-level data were collected during each studenttray observation for grade and gender. School-level demographics were obtained from publicly available data from NYCDOE for the 2014-2015 school year for total student enrollment (school size), \% Black, \% Hispanic, and \% FRPL eligible.

\section{Procedures}

SOCAFE: fruit and vegetable consumption. The SOCAFE utilizes a protocol adopted from prior food consumption assessment research ${ }^{28-30}$ and further refined with personal communications with the research lead author and her team (Suzanne Domel Baxter, PhD, Kathleen Collins, BS, and Alyssa Smith, MPH, e-mail communication, April 14, 2015, in-person meetings, April 30-May 1, 2015). Research staff underwent 36 hour days of training, with the third day of training comprising 3 observation sessions with a fellow research staff member to determine their inter-rater reliability (IRR) percentage match scores; the mean training IRR percentage match scores was over $95 \%$ for food items on tray, and over $78 \%$ for amounts of food items eaten. There were 10 research staff in Fall 2015, and 12 research staff in Spring 2016 (9 of which were the same from Fall 2015). The research staff paired off for 20 IRR assessments comprising 80 lunch-tray observations through the duration of data collection in Fall 2015 and Spring 2016. The mean IRR percentage match for school food items on a tray was 99\%, and for amounts of items eaten was $86 \%$. For 
the larger primary study, selection and consumption of food items from all food groups of the school lunch meal were collected. For the current investigation, only school lunch F\&V selection and consumption data were extracted and processed for analysis.

The data collection format was a team of 4 research staff completing observations of a sample of 16 second and 16 third grade students from 2 different lunch periods each day. The lead research staff worked with school staff to determine the table(s) where the second or third grade students sat, and assigned each research staff to a table section. Research staff skipped over students that did not take any school lunch, and continued with adjacent students with school lunch such that 4 students (all sitting within reasonably close proximity to each other) were selected for observation.

The observations were anonymous without identification of the students, and the selected students formed a unique convenience sample each lunch observation day. Research staff were trained to be minimally intrusive and as inconspicuous as possible. Students were blind to this ongoing study and we obtained waiver of consent from both institutional review boards. No students reported incidents of distress during data collection.

Prior to the lunch observations each day, F\&V options from the standardized school lunch meal and the salad bar were prefilled into the "Item" column in the SOCAFE form for quick reference. Each research staff observed up to 4 students from the moment they sat down with their school lunch trays until they disposed of their food and left the cafeteria. For each F\&V option offered, research staff checked off in the "No," "Yes," or "2nd Serving" in the "on tray" section of the SOCAFE form. Research staff observed the students as they ate, and tracked the progress of the percentage of each F\&V eaten by checking off the columns with the corresponding percentage category. When students disposed of their lunch trays, the research staff would circle the final percentage category for each $F \& V$.
Lunch PIECES: school lunch environmental factors. Research staff visually observed the school cafeteria and lunch process, and completed the checklist items that assessed the presence or intensity of various school lunch environmental factors. Research staff responded to each item in Lunch PIECES based on a standardized scoring rubric. Any questions and uncertainties for which it was challenging to determine a qualified "Yes" or "No" response were noted by research staff, and were reviewed later with the scoring rubric, and/or with the first author.

\section{Data Analyses}

Hierarchical linear modeling (HLM) was used to account for students being clustered within schools, with individual-level independent variables entered in the first level, and school-level independent variables entered in the second level. Four different models were run for the outcome variables of $\mathrm{F} \& \mathrm{~V}$ consumption within the students that had the item on their trays and across all students. Only the school lunch environmental factors relevant to F\&V consumption were included in each linear regression model (Table 1). Factors were included simultaneously, with the Yes/No categorical factors included as dummy variables. First-level variables were: grade (coded as third grade dummy variable), gender (coded as Male dummy variable), and also school term (coded as Spring dummy variable). Second-level variables were: school size, \% Black, \% Hispanic, \% FRPL, and also school type (coded as WITS dummy variable). The models also included cross-level interaction of school term (Fall or Spring) and school type (Control or WITS) to further account for any potential interaction effects.

The consumption outcomes were not normally distributed, with high frequencies of 0 cups for both fruit (428 observations, or $48.8 \%$ ) and vegetable (731 observations, or $83.8 \%)$. The values of these outcomes were transformed with square rooting. Values of cups consumed are presented as adjusted means that have been squared back, and are presented only when the school lunch environmental factor is significant at $P<.05$. Analyses were conducted using SPSS version 23 (IBM Corp, Armonk, NY; 2016) and HLM 7.01 (Scientific Software International, Inc, Skokie, IL; 2013).

\section{RESULTS}

The 877 student-tray observations represented $50.2 \%$ boys and $51.8 \%$ third graders. Students were from 14 NYC public schools with an average of $40.6 \%$ Black, $48.8 \%$ Hispanic, 94.1\% FRPL, and 581 students enrolled. This study collected 2 days of data for each school, with a total of 40-100 student-tray observations per school. Unadjusted mean consumption of fruit was .189 cups, and unadjusted mean consumption of vegetable .045 cups (Table 4).

Nineteen $(30.7 \%)$ of the 62 lunch periods had lunch after recess (Table 1). Thirteen (31.8\%) of the 65 lunch periods had fruits preplated on lunch trays, whereas 39 (60.0\%) of the 65 lunch periods had vegetables preplated on lunch trays. Twenty (31.8\%) of the 63 lunch periods had 2 or more fruit options, whereas only $11(16.9 \%)$ of the 65 lunch periods had 2 or more vegetable options. Forty $(61.5 \%)$ of the 65 lunch periods served sliced or precut fruit. The unadjusted mean wait time for the first student to get lunch was 4.6 minutes and the unadjusted mean duration of school lunch was 14.3 minutes, with only 9 (13.9\%) of the 65 observed lunch periods that were 20 minutes or longer.

\section{Fruit Consumption}

For sliced or precut fruits, sliced apples were most commonly served, appearing in 19 (29.2\%) out of 65 of the lunch periods observed (Table 2). For whole fruits, apples and pears were both most commonly served, appearing in $16(24.6 \%)$ out of 65 of the lunch periods observed. For students that were observed to have the fruit item on their trays, unadjusted mean consumption was highest for apple sauce, at .406 cups, followed by 
Table 2. Frequency and Unadjusted Mean Consumption of Fruit Item Options Served Sliced/Precut or Whole, Out of 65 Observed Lunch Periods

\begin{tabular}{|c|c|c|c|c|}
\hline Sliced or Whole Fruit Item & $\begin{array}{l}\text { Frequency of } \\
\text { Lunch Periods }\end{array}$ & $\begin{array}{l}\% \text { of Observed } \\
\text { Lunch Periods }\end{array}$ & $\begin{array}{l}\text { Number of Observed } \\
\text { Student-Lunch Trays } \\
\text { with Fruit Item }\end{array}$ & $\begin{array}{c}\text { Cups of } \\
\text { Fruit Consumed, } \\
\text { mean (SD) }\end{array}$ \\
\hline
\end{tabular}

Sliced/precut

$\begin{array}{lrrrr}\text { Apple sauce } & 2 & 3.1 & 8 & .406(.438) \\ \text { Apple slices } & 19 & 29.2 & 262 & .234(.525) \\ \text { Cantaloupe } & 2 & 3.1 & 32 & .081(.332) \\ \text { Honeydew } & 2 & 3.1 & 18 & .236(.562) \\ \text { Orange slices } & 4 & 6.2 & 32 & .059(.269) \\ \text { Peach chunks (frozen) } & 12 & 18.5 & 148 & .136(.426) \\ \text { Pear chunks (in juice) } & 4 & 6.2 & 60 & .079(.344) \\ \text { Pineapple chunks } & 2 & 3.1 & 32 & .005(.047) \\ \text { Whole } & & & & .082(.309) \\ \text { Apple (whole) } & 16 & 24.6 & 244 & .247(.454) \\ \text { Banana } & 7 & 10.8 & 54 & .189(.472) \\ \text { Orange (whole) } & 5 & 7.7 & 76 & .083(.345) \\ \text { Pear (whole) } & 16 & 24.6 & 209 & \end{array}$

SD indicates standard deviation.

Table 3. Frequency and Unadjusted Mean Consumption of Vegetable Item Options Served, Out of 65 Observed Lunch Periods

\begin{tabular}{lcccc} 
Vegetable Item & $\begin{array}{c}\text { Frequency of } \\
\text { Lunch Periods }\end{array}$ & $\begin{array}{c}\text { \% of Observed } \\
\text { Lunch Periods }\end{array}$ & $\begin{array}{c}\text { Number of Observed } \\
\text { Student-Lunch Trays } \\
\text { with Vegetable Item }\end{array}$ & $\begin{array}{c}\text { Cups of Vegetable } \\
\text { Consumed, mean (SD) } \\
\text { Baby carrot }\end{array}$ \\
\hline Broccoli & 10 & 12.3 & 117 & $.018(.142)$ \\
Chickpea salad & 4 & 15.4 & 121 & $.032(.233)$ \\
Corn & 10 & 6.2 & 53 & $.018(.128)$ \\
Cucumber & 5 & 15.4 & 128 & $.098(.423)$ \\
Egg roll vegetable & 2 & 7.7 & 64 & $.023(.187)$ \\
Garden salad & 2 & 3.1 & 32 & $.034(.269)$ \\
Green bean & 9 & 3.1 & 36 & $.014(.167)$ \\
Hummus & 2 & 13.8 & 130 & $.013(.118)$ \\
Lettuce \& tomato & 2 & 3.1 & 32 & $.004(.044)$ \\
Pickles & 2 & 3.1 & 32 & $.002(.018)$ \\
Plantain & 2 & 3.1 & 32 & $.031(.246)$ \\
Sofrito black bean & 4 & 6.2 & 48 & $.196(.476)$ \\
Sweet potato & 7 & 10.8 & 81 & $.001(.011)$ \\
Zucchini & 16 & 24.6 & 191 & $.025(.194)$ \\
\hline
\end{tabular}

SD indicates standard deviation. 
Cups of Fruit Consumed, mean (SD)

Overall $.189(.236)$

Cups of Vegetable Consumed, mean (SD)

Gender

Girls

Boys

Grade

2nd

3rd

School term

Fall 2015

Spring 2016
$.193(.235)$

$.185(.238)$

$.175(.231)$

$.202(.241)$

$.164(.228)$

$.212(.242)$
$.046(.139)$

$.048(.145)$

$.087(.134)$

$.039(.123)$

$.051(.153)$

.025 (.094)

$.064(.168)$

SD indicates standard deviation.

banana, honeydew, and apple slices, at .234 to .247 cups.

\section{Slicing of fruits may contribute to greater fruit consumption during school lunch.}

When fruits were sliced or precut, compared to whole fruits being served, the consumption of fruit was higher by .231 cups within students with fruit on their trays $(P=.02$; Table 5), and higher by .163 cups across all students $(P=.007)$. When fruits were preplated on lunch trays, compared to when students choose to select fruit item or not, consumption of fruit was lower by .074 cups within students that had fruit on their tray $(P=.041)$. When lunch was after recess, compared to when lunch was before recess, the consumption of fruit was higher by .080 cups across all students $(P<.001)$. Having 2 or more fruit options available, presenting whole fruits in an attractive serving bowl, wait time before getting school lunch, and time duration of school lunch were not found to have a significant relationship with fruit consumption.

\section{Vegetable Consumption}

Sweet potato was the most commonly served vegetable, appearing in $16(24.6 \%)$ out of 65 of the lunch periods observed (Table 3 ). Broccoli and corn were the next 2 most commonly served, both appearing in $10(15.4 \%)$ out of 65 of the lunch periods observed. For students that were observed to have the vegetable item on their trays, unadjusted mean consumption was highest for plantain (4 lunch periods), at .196 cups, followed by corn, at .098 cups. Unadjusted mean consumption of all the other vegetable items was $<.050$ cups.

When lunch was after recess, compared to when lunch was before recess, the consumption of vegetables was higher by .007 cups across all students $(P=.043$; Table 6). When vegetables were preplated on lunch trays, compared to when students choose to select vegetable item or not, the consumption of vegetables was higher by .024 cups across all students $(P<.001)$. When there were 2 or more vegetable options available, compared to when there was only one vegetable option available, the consumption of vegetables was higher by .009 cups across all students $(P=.038)$. Positioning vegetables as the first item to be served in the lunch line, wait time before getting school lunch, and time duration of school lunch, were not found to have a significant relationship with vegetable consumption. However, school term was found to be a significant factor in the consumption of vegetables across all students, with consumption higher in Spring 2016 by .009 cups than in Fall 2015 $(P=.015)$.

\section{DISCUSSION}

The current investigation found that sliced or precut fruit was associated with higher fruit consumption in our sample of second and third graders across 14 NYC low-income public elementary schools. These findings were similar to previous research that found more students ate fruit when fruits were sliced, as opposed to served whole. $^{24,25}$ Previous qualitative work revealed that elementary children found whole fruits to be inconveniently large, ${ }^{25}$ and so slicing and precutting of fruit into smaller more chewable pieces may increase the likelihood that children are able to eat fruit. A prime example would be apples: children could have difficulties biting into the skin with their front teeth when served whole, but could easily bite into or fit a piece in their mouths when served sliced. The number of lunch periods that served sliced or precut fruit (total 47) was similar to the number that served whole fruits (total 44) in the observed 65 lunch periods, suggesting that the barriers of cost or time needed for sliced or precut fruit might not be as high as expected, or that school administration teams were willing to dedicate efforts to overcome them.

Having lunch scheduled after recess was also found to be positively associated with fruit consumption (.080 cups higher) and, to a lesser extent, vegetable consumption (.007 cups higher). Contrasted to previous research with $\mathrm{F} \& \mathrm{~V}$ consumption as 


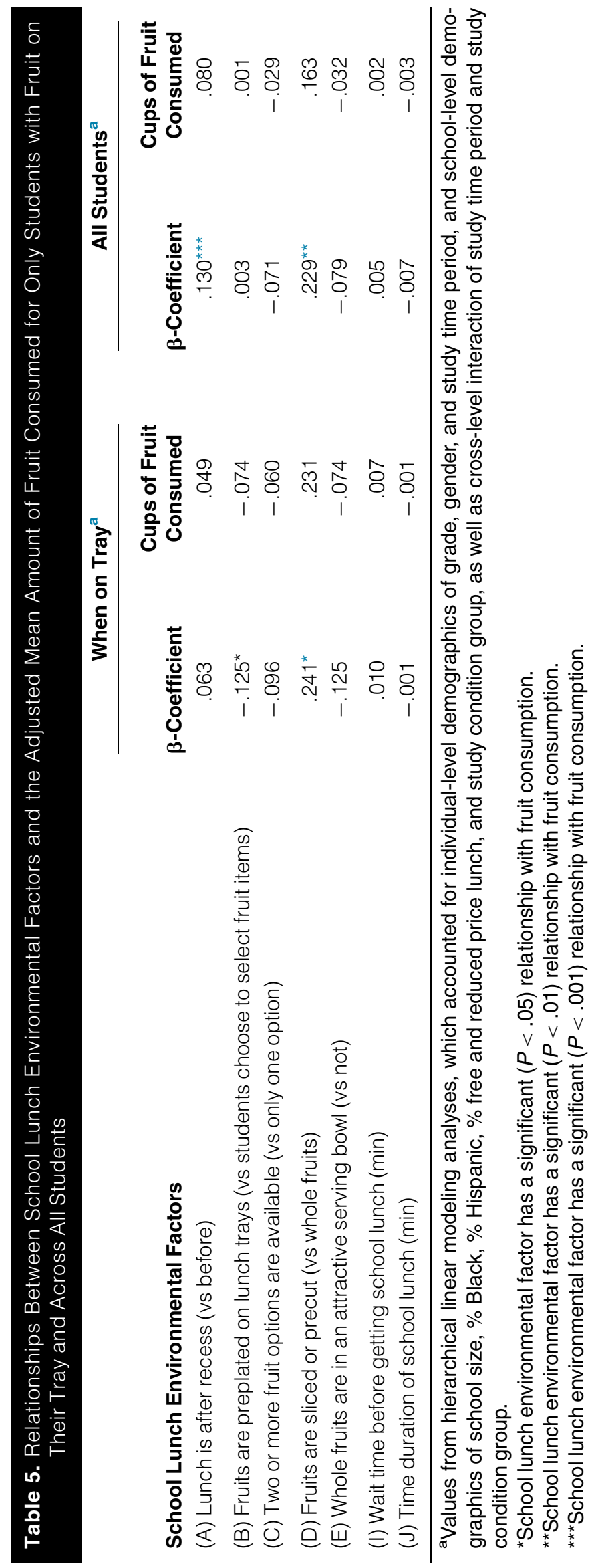

one combined outcome, ${ }^{17,19,20}$ this study disentangled the relationship and identified the greater association of scheduling lunch after recess with fruit consumption, mirroring recently published findings. ${ }^{18}$ It is possible that greater impact on fruit consumption than vegetable consumption from scheduling lunch after recess was driven by some children preferring fruits after recess because they are more juicy and thus more thirst-quenching, and also sweeter than vegetables. ${ }^{36,37}$

Scheduling lunch after recess might minimize the incentive for students to rush through lunch in order to go out for recess on time or even earlier. ${ }^{20}$ This decreased time pressure could potentially allow students to have more opportunities to eat more components and greater amounts of their school lunch. Wait time and time duration of lunch were not found to be significant factors impacting $\mathrm{F} \& \mathrm{~V}$ consumption. Although there were no federal or state requirements for the length of school lunch periods, NYCDOE did recommend providing students at least 20 minutes to eat school lunch. ${ }^{38}$ However, the mean duration of school lunch found in this study was $<20$ minutes, with only a small proportion of the observed lunch periods covering longer time durations of 20 minutes or longer. Perhaps if the distribution of school lunch periods covered longer time durations in the range upwards of 25 to 30 minutes like those tested in previous research studies, ${ }^{15,16}$ the factor of time duration could be significant.

Preplating of fruits on the lunch trays was found to have a negative association with fruit consumption (.074 cups lower) within students that had fruit on their trays, while preplating of vegetables on the lunch trays was found to have a positive but very small association with vegetable consumption across all students (.024 cups higher). As was discussed in previous studies with similar findings, food wastage is of concern if preplating food items does not lead to a sizeable increase in consumption. ${ }^{21,39}$ It is thus important to understand the rationale of why different schools choose to preplate food items or not. Reasons to 


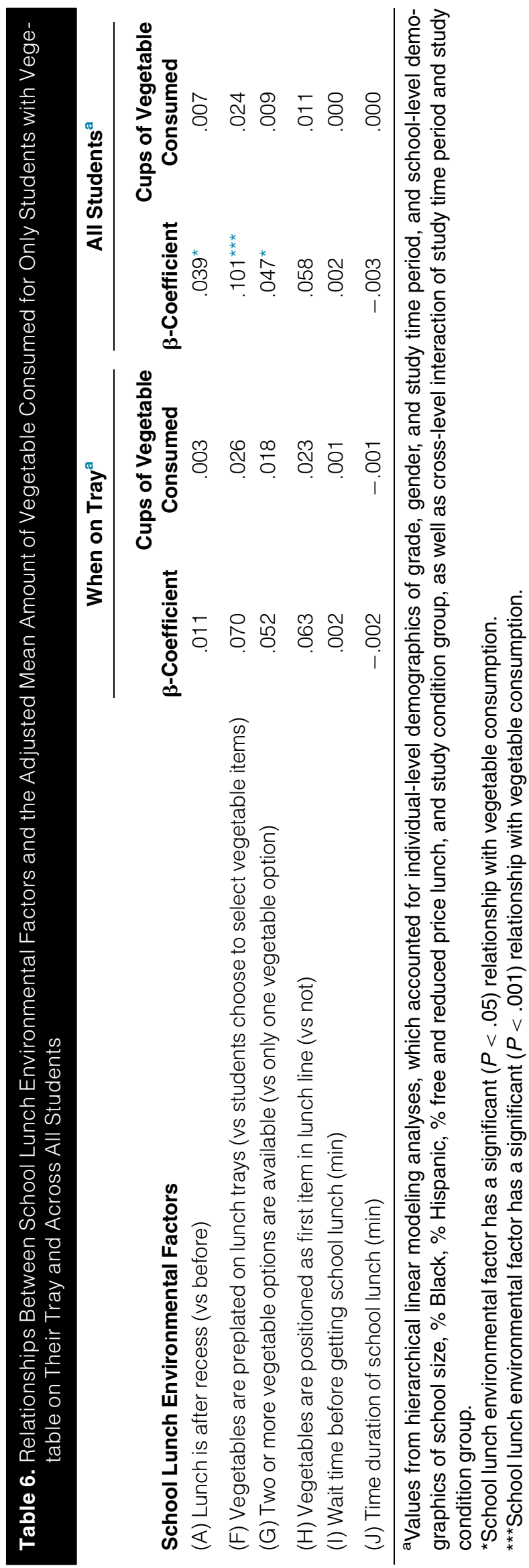

preplate F\&V items on school lunch trays could also be to save school staff time and move the lunch line along faster, to ensure the meals served meet reimbursable criteria, or to increase the chances of students trying $\mathrm{F} \& \mathrm{~V}$. Understanding which combination of reasons behind this practice could help determine if preplating is worth the tradeoff if the change in amount of F\&V consumed is not expected to be sizeable or positive.

Within students with vegetables on their trays, no school lunch environmental factors tested were significantly related to vegetable consumption. Across all students, the significant factors, including that of school term, led to small increments of .007 to .024 cups higher in vegetable consumption. Of the various vegetable item options served, plantain and corn had the highest consumption, and both are classed in the USDA starchy vegetable category. ${ }^{1,8}$ It should be cautioned that this study was not designed to compare students' consumption choices between different vegetable options. However, the presented descriptive shows that the unadjusted mean consumption of all the other vegetable items, which are not classed in the USDA starchy vegetable category, was $<.050$ cups. This indicates that more solution options should be explored for encouraging children to consume more vegetables from the various categories.

\section{Limitations}

The study design was cross-sectional and explored the associations of various factors with F\&V consumption, and did not test for the causation effects longitudinally. It is possible that these associations exist due to some circumstance not measured. However, for the factors analyzed, because previous work has tested these factors independently, we have reasonably high confidence to conclude that our findings are congruent with those in the field. Future studies can follow-up on the findings from this study and experimentally test out the significant factors in various combinations, in the same schools, and determine the longitudinal 
impact of these factors on $\mathrm{F} \& \mathrm{~V}$ consumption.

In this current investigation, some fruits were never served whole (eg, peaches, cantaloupe, pineapple) and one fruit (banana) was never served sliced/precut. We did not directly compare the sliced/precut version of a particular fruit (eg, apple slices) to its whole fruit counterpart (eg, a whole apple); rather, we compared the effects of all fruits served sliced/ precut vs all whole fruits served. Thus, it is unclear whether students are increasing consumption because of fruit being cut/sliced or for other reasons such as being more sweettasting, more attractively presented, or more generally well liked. However, our finding also mirrored the prior findings from studies looking at only 1 or 2 fruit options. ${ }^{24,25}$

Food consumption data were based on observation of percentage of one standard serving eaten. There was no weighing of students' food trays for the portions that were served, and so it was assumed that staff members followed regulations and served one standard serving of .5 cup of $\mathrm{F} \& \mathrm{~V}$ for elementary school students. There is a potential confounder of varying serving size across staff members from different schools. However, the unique features of each school that attribute to clustering effects were controlled for with HLM.

\section{Strengths}

The total sample of 14 schools in this study is much larger than what is found in many other studies, which usually have fewer than 10 schools, oftentimes with only 1 or 2 schools. ${ }^{15-17,23-25,27,39}$ This study also collected 2 days of data for each school, with a total of 40-100 student-tray observations per school.

The use of observation of food consumption also provided more accurate data. Using observations in a study sample of children is more advantageous than traditional food consumption collection method of food diaries or recall, since it is not reliant on inaccurate reports by children. ${ }^{29,30}$ Observations also provide an edge over the use of digital photography or weighing of plate waste in its ability to capture food item trades, which is a common occurrence among children during school lunch. $^{28}$ Observations also limit missing data when the whole fruit or packet of sliced fruit is missing in postmeal photographs. ${ }^{40}$

The 7 increments for amount eaten $(0 \%, 10 \%, 25 \%, 50 \%, 75 \%$, $100 \%, \geq 100 \%)$ used in this study provided increased sensitivity compared to some previous studies, which utilized larger increments $(0 \%, 50 \%, \quad 100 \%)$ for amount eaten. ${ }^{20-23,25}$ Studies with similar findings, such as by Swanson et al $(2009)^{24}$ and Wansink et al (2013), ${ }^{25}$ chose to record and present their data as proportion of students that ate at least half a serving or more, instead of actual mean cups of fruit consumed. The current investigation used a more sensitive measurement of consumption data, and could quantify that fruit consumption was higher by almost a quarter cup (or a half of a usual serving) of school lunch fruit, within the students that had sliced or precut fruit on their trays. This study also evaluated various school lunch environmental factors simultaneously to determine the strength of each factor's impact on F\&V consumption. Many other studies in the literature limited explorations of only 1 or 2 school lunch environmental factors at a time. These other studies also have study design aspects that limit the strength of their conclusions, such as a low number of schools (limiting power) or a sample based only on convenience (limiting generalizability). This study combined analysis of various school lunch environmental factors simultaneously, and thus allowed for identifying the key significant factors that impact the consumption of $F \& V$.

\section{IMPLICATIONS FOR RESEARCH AND PRACTICE}

The findings from this study indicate that some previously identified school lunch environmental factors could have influences on the $F \& V$ consumption. Interventions designed to increase $\mathrm{F} \& \mathrm{~V}$ consumption could thus consider incorporating steps to manipulate these factors to improve the impact of their programming. At the same time, school administration teams could also be the ones that make these changes in their schools, without relying on external intervention programming. Some of these changes, such as changing the lunch and recess order, could be simple and within their domain to execute, without additional costs, and could lead to measurable improvements in school lunch $\mathrm{F} \& \mathrm{~V}$ consumption. However, the resultant improvements in health due to the change of this one school lunch environmental factor alone is likely unobservable in the short term, especially since it is associated with less than a tenth of a cup higher F\&V consumption. Slicing of fruits, though likely to incur some additional resources, seems the most promising in meaningfully increasing fruit consumption, and should be further tested in large-scale studies to evaluate its long-term impact.

\section{ACKNOWLEDGMENTS}

Financial support for this work from 2015 to 2017 was provided by Wellness in the Schools, and the Laurie M. Tisch Illumination Fund. We would like to thank the following people: doctoral student Matthew Dallefeld, MS for his organization and participation in all of the data collection; Suzanne Domel Baxter, PhD, RD, LD, FADA, FAND, Kathleen Collins, BS, and Alyssa Smith, MPH for their guidance in conducting direct meal observations in school cafeterias; Margarida Siopa, MPH for her assistance with SOCAFE and Lunch PIECES instrument design and piloting. We would also like to thank New York City Department of Education for providing school-level data.

\section{REFERENCES}

1. US Department of Health and Human Services, US Department of Agriculture. 2015-2020 Dietary Guidelines for Americans. 8th Edition. 2015. https://health.gov/dietaryguidelines/ 2015/resources/2015-2020_Dietary_ Guidelines.pdf. Accessed September 17, 2018

2. National Cancer Institute, Division of Cancer Control \& Population Sciences. 
Usual Dietary Intakes: Food Intakes, U.S. Population, 2007-10. 2015. http:// epi.grants.cancer.gov/diet/usualintakes/pop/2007-10/. Accessed August 27, 2018.

3. Boeing $\mathrm{H}$, Bechthold A, Bub A, et al. Critical review: vegetables and fruit in the prevention of chronic diseases. Eur J Nutr. 2012;51:637-663.

4. Mikkila V, Rasanen L, Raitakari OT, Pietinen P, Viikari J. Longitudinal changes in diet from childhood into adulthood with respect to risk of cardiovascular diseases: the Cardiovascular Risk in Young Finns Study. Eur J Clin Nutr. 2004;58:1038-1045.

5. Van Duyn MA, Pivonka E. Overview of the health benefits of fruit and vegetable consumption for the dietetics professional: selected literature. J Am Diet Assoc. 2000;100:1511-1521.

6. Amre DK, D'Souza S, Morgan K, et al. Imbalances in dietary consumption of fatty acids, vegetables, and fruits are associated with risk for Crohn's disease in children. $A m \mathrm{~J}$ Gastroenterol. 2007;102:2016-2025.

7. Kraak VI, Story M, Swinburn BA. Addressing barriers to improve children's fruit and vegetable intake. Am J Clin Nutr. 2013;97:653-655.

8. Food and Nutrition Service, United States Department of Agriculture. Nutrition standards in the national school lunch and school breakfast programs. Final rule. Fed Regist. 2012;77:4088-4167.

9. Produce for Better Health Foundation. State of the plate: 2010 study on America's consumption of fruits and vegetables. 2010. http:// www.pbhfoundation.org/pdfs/about/ res/pbh_res/stateplate.pdf. Accessed August 27, 2018.

10. Produce for Better Health Foundation. State of the plate: 2015 study on America's consumption of fruit \& vegetables. 2015. http://www. pbhfoundation.org/pdfs/about/res/ pbh_res/State_of_the_Plate_2015_ WEB_Bookmarked.pdf. Accessed August 27, 2018.

11. Larson NI, Neumark-Sztainer D, Hannan PJ, Story M. Trends in adolescent fruit and vegetable consumption, 1999-2004: project EAT. Am J Prev Med. 2007;32:147-150.

12. Reinaerts E, de Nooijer J, Candel M, de Vries N. Explaining school children's fruit and vegetable consumption: the contributions of availability, accessibility, exposure, parental consumption and habit in addition to psychosocial factors. Appetite. 2007;48: 248-258.

13. Reynolds KD, Hinton AW, Shewchuk RM, Hickey CA. Social cognitive model of fruit and vegetable consumption in elementary school children. $J$ Nutr Educ. 1999;31:23-30.

14. Wansink B. Environmental factors that increase the food intake and consumption volume of unknowing consumers. Annu Rev Nutr. 2004;24:455-479.

15. Bergman EA, Buergel NS, Englund TF, Femrite A. The relationship between the length of the lunch period and nutrient consumption in the elementary school lunch setting. J Child Nutr Manag. 2004;28(2). https://schoolnutrition. org/uploadedFiles/5_News_and_Publications/4_The_Journal_of_Child_Nutrition_and_Management/Fall_2004/6bergman.pdf. Accessed August 27, 2018.

16. Cohen JFW, Jahn JL, Richardson S, Cluggish SA, Parker E, Rimm EB. Amount of time to eat lunch is associated with children's Selection and Consumption of School Meal Entree, Fruits, Vegetables, and Milk. J Acad Nutr Diet. 2016;116:123-128.

17. Bergman EA, Buergel NS, Englund TF, Femrite A. The relationship of meal and recess schedules to plate waste in elementary schools. J Child Nutr Manag. 2004;28 (2). https://schoolnutrition.org/uploadedFiles/5_News_and_Publications/4_ The_Journal_of_Child_Nutrition_and_ Management/Fall_2004/5-bergman. pdf. Accessed August 27, 2018.

18. Chapman LE, Cohen J, Canterberry M, Carton TW. Factors associated with school lunch consumption: reverse recess and school "brunch". J Acad Nutr Diet. 2017;117:1413-1418.

19. Fenton K, Rosen NJ, Wakimoto P, Patterson T, Goldstein LH, Ritchie LD. Eat lunch first or play first? Inconsistent associations with fruit and vegetable consumption in elementary school. $J$ Acad Nutr Diet. 2015;115:585-592.

20. Price J, Just DR. Lunch, recess and nutrition: responding to time incentives in the cafeteria. Prev Med. 2015;71:27-30.

21. Just D, Price J. Default options, incentives and food choices: evidence from elementary-school children. Public Health Nutr. 2013;16:2281-2288.

22. Just DR, Lund J, Price J. The role of variety in increasing the consumption of fruits and vegetables among children. Agric Resour Econ Rev. 2012;41:72-81.
23. Hanks AS, Just DR, Wansink B. Smarter lunchrooms can address new school lunchroom guidelines and childhood obesity. J Pediatr. 2013;162: 867-869.

24. Swanson M, Branscum A, Nakayima PJ. Promoting consumption of fruit in elementary school cafeterias. The effects of slicing apples and oranges. Appetite. 2009;53:264-267.

25. Wansink B, Just DR, Hanks AS, Smith LE. Pre-sliced fruit in school cafeterias: children's selection and intake. Am J Prev Med. 2013;44:477-480.

26. Wansink B, Hanks AS. Slim by design: serving healthy foods first in buffet lines improves overall meal selection. PLoS One. 2013;8:e77055.

27. Elsbernd SL, Reicks MM, Mann TL, Redden JP, Mykerezi E, Vickers ZM. Serving vegetables first: a strategy to increase vegetable consumption in elementary school cafeterias. Appetite. 2016;96:111-115.

28. Baxter SD, Thompson WO, Davis HC. Trading of food during school lunch by first- and fourth-grade children. Nutr Res. 2001;21:499-503.

29. Baxter SD, Thompson WO, Litaker MS, Frye FH, Guinn CH. Low accuracy and low consistency of fourthgraders' school breakfast and school lunch recalls. $J$ Am Diet Assoc. 2002;102:386-395.

30. Baxter SD, Thompson WO, Litaker MS, et al. Accuracy of fourth-graders' dietary recalls of school breakfast and school lunch validated with observations: in-person versus telephone interviews. J Nutr Educ Behav. 2003;35: 124-134

31. Hanks AS, Wansink B, Just DR. Reliability and accuracy of real-time visualization techniques for measuring school cafeteria tray waste: validating the quarter-waste method. J Acad Nutr Diet. 2014;114:470-474.

32. Tipton E. Improving generalizations from experiments using propensity score subclassification: assumptions, properties, and contexts. J Educ Behav Stat. 2013;38:239-266.

33. Adams MA, Bruening M, Ohri-Vachaspati P, Hurley JC. Location of school lunch salad bars and fruit and vegetable consumption in middle schools: a crosssectional plate waste study. $J$ Acad Nutr Diet. 2016;116:407-416.

34. Kim SA, Moore LV, Galuska D, et al. Vital signs: fruit and vegetable intake among children - United States, 2003 
-2010. MMWR Morb Mortal Wkly Rep. 2014;63:671-676.

35. NYC SchoolFood. School lunch menus. http://www.schoolfoodnyc. org/schoolfood/MenusDailyDisplay. aspx. Accessed June 6, 2017.

36. Mennella JA, Ventura AK. Understanding the basic biology underlying the flavor world of children. Curr Zool. 2010;56:834-841.

37. Petrauskiene A, Zaltauske V, Albaviciute E. Family socioeconomic status and nutrition habits of 7-8 year old children: cross-sectional Lithuanian COSI study. Ital J Pediatr. 2015;41:34.

38. NYC Department of Education. New York City Department of Education Wellness Policy. 2017. https://www. schools.nyc.gov/docs/default-source/ default-document-library/2017-wellness-policy-english. Accessed September 21, 2018.

39. Miller N, Reicks M, Redden JP, Mann T, Mykerezi E, Vickers Z. Increasing portion sizes of fruits and vegetables in an elementary school lunch program can increase fruit and vegetable consumption. Appetite. 2015;91:426-430.

40. Swanson M. Digital photography as a tool to measure school cafeteria consumption. J Sch Health. 2008;78:432437.

\section{Learn About SNEB Position}

\section{Papers-check out our policy page}

https://www.jneb.org/content/policy_position_papers 